\title{
ON BONNESEN-STYLE ISOPERIMETRIC INEQUALITIES FOR $n$-SIMPLICES
}

\author{
WEN WANG AND Shiguo YANG
}

Abstract. In this paper, we derive some Bonnesen-style inequalities referring to $n$-dimensional simplices in the sprit of isoperimetric problems. These inequalities combine various metric quantities of simplices and yield, in several cases, characterizations of regular simplices. Also related reverse Bonnesen-style inequalities are derived.

Mathematics subject classification (2010): 51K05, 51K16, 52A38, 52A40.

Keywords and phrases: (Reverse) Bonnesen-style inequalities, circumradius, geometric inequality, inradius, isoperimetric deficit, (regular) simplex, width.

\section{REFERENCES}

[1] R. Osserman, The isoperimetric inequalities, Bull. Amer. Math. Soc. 84 (1978), 1182-1238.

[2] B. Fuglede, Bonnesen inequality for the isoperimetric deficiency of closed curves in the plane, Geometriae Dedicata 38 (1991), 283-300.

[3] R. Osserman, Bonnesen-style isoperimetric inequalities, Amer. Math. Monthly 1 (1979), 1-29.

[4] J. BoKOWSKI AND E. HeIL, Integral representation of quermassintegrals and Bonnesen-style inequalities, Arch. Math. (Basel) 47 (1986), 1, 79-89.

[5] T. Bonnesen, Les problems des isoperimetres et des isepiphanes, Gauthier-Villars, Paris, 1929.

[6] T. Bonnesen And W. Fenchel, Theorie der konvexen Körper, 2nd ed., Berlin-Heidelberg- New York, 1974.

[7] J. Z. Zhou, Y. W. XiA And C. Zeng, Some new Bonnesen-style inequalities, J. Korean Math. Soc. 48 (2011), 2, 421-430.

[8] Q. J. MAO, On the isoperimetric deficit of a simplex and of a polygon, Geometriae Dedicata 62 (1996), 93-98.

[9] G. Zhang, J. Zhou, Containment Measures in Integral Geometry, Integral Geometry and Convexity, Singapore: World Scientific, 2006, 153-168.

[10] H. MARTini, AND Z. MustafaEV, Extensions of a Bonnesen-style inequality to Minkowski spaces, Math Inequal. Appl. 11 (2008), 739-748.

[11] D. S. Mitrinović, J. E. PeČarić And V. Volenec, Recent Advances in Geometric Inequalities, Kluwer Academic, Dordrecht, 1989.

[12] J. C. KuAng, Applied Inequalities, Shandong Sci. and Technol. Press, Jinan, 2004, 255-261.

[13] L. A. SAnTAló, Integral Geometry and Geometric Probability, Reading, MA: Addison-Wesley, 1976.

[14] R. AleXander, The width and diameter of a simplex, Geometriae Dedicata 6 (1977), 87-94.

[15] R. K. GuY, Problems, Lecture Notes in Math. 490, "The Geometry of Metric and Linear Space", Springer-Verlag, 1975.

[16] L. Fejes Toth, Extremum properties of regular polytopes, Acta. Math. Acad. Sci. Hungar. 6 (1955), 143-146.

[17] M. S. KLAMKIN, Inequality for a simplex, SIAM Rev. 27 (1985), 14, 576.

[18] S. G. YANG, An inequality for a simplex and its applications, Geometriae Dedicata 55 (1995), 195198.

[19] L. YAng, And J. Z. Zhang, Metric equation and Sallee conjecture, Acta Mathematica Sinica 26 (1983), 4, 488-493. 
[20] W. WANG, AND S. G. YANG, A new Neuberg-Pedoe type inequality for two tetrahedrons with applications, International Journal of Geometry 2 (2013), 1, 60-67. 